\title{
Natural products in diabetes research: quantitative literature analysis
}

\author{
Andy Wai Kan Yeung a , Nikolay T. Tzvetkov ${ }^{\text {b,c }}$ (D), Alessandra Durazzo ${ }^{d}$ \\ Massimo Lucarini $^{d}$ (D), Eliana B. Souto ${ }^{e, f}$ (D), Antonello Santini ${ }^{9}$ (D), \\ Ren-You Gan ${ }^{\text {h }}$, Artur Jozwiki, Weronika Grzybeki, Jarosław O. Horbańczuki, \\ Andrei Mocan ${ }^{\mathrm{j}, \mathrm{k}}$, Javier Echeverría', Dongdong Wang ${ }^{\mathrm{i}, \mathrm{m}, \mathrm{n}}$ (D) and \\ Atanas G. Atanasov ${ }^{\mathrm{c}, \mathrm{i}, \mathrm{o}, \mathrm{p}}$
}

${ }^{a}$ Oral and Maxillofacial Radiology, Applied Oral Sciences and Community Dental Care, Faculty of Dentistry, The University of Hong Kong, Hong Kong, China; ${ }^{\mathrm{b}}$ Department of Biochemical Pharmacology and Drug Design, Institute of Molecular Biology "Roumen Tsanev", Bulgarian Academy of Sciences, Sofia, Bulgaria; 'Institute of Neurobiology, Bulgarian Academy of Sciences, Sofia, Bulgaria; ${ }^{\mathrm{d} C R E A-R e s e a r c h}$ Centre for Food and Nutrition, Rome, Italy; ${ }^{\mathrm{e}}$ Department of Pharmaceutical Technology, Faculty of Pharmacy, Polo das Ciências da Saúde, University of Coimbra, Coimbra, Portugal; ${ }^{\mathrm{f} C E B}$-Centre of Biological Engineering, University of Minho, Braga, Portugal;

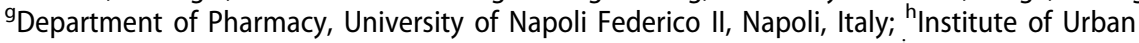
Agriculture, Chinese Academy of Agricultural Sciences, Chengdu, China; 'Institute of Genetics and Animal Biotechnology, Polish Academy of Sciences, Magdalenka, Poland; 'Department of Pharmaceutical Botany, Faculty of Pharmacy, "Iuliu Haţieganu" University of Medicine and Pharmacy, Cluj-Napoca, Romania; ${ }^{k}$ Laboratory of Chromatography, Institute of Advanced Horticulture Research of Transylvania, University of Agricultural Sciences and Veterinary Medicine, Cluj-Napoca, Romania; 'Departamento de Ciencias del Ambiente, Facultad de Química y Biología, Universidad de Santiago de Chile, Santiago, Chile; ${ }^{\mathrm{m}}$ Institute of Clinical Chemistry, University Hospital Zurich, Schlieren, Switzerland; ${ }^{n}$ The Second Affiliated Hospital of Guizhou University of Traditional Chinese Medicine, Guiyang, China; ${ }^{\circ}$ Ludwig Boltzmann Institute for Digital Health and Patient Safety, Medical University of Vienna, Vienna, Austria; ${ }^{\mathrm{P}}$ Department of Pharmacognosy, University of Vienna, Vienna, Austria

\section{ABSTRACT}

The current study aimed to identify which natural products and which research directions are related to the major contributors to academic journals for diabetes therapy. Bibliometric data were extracted from the Web of Science online database using the search string TOPIC = ("natural product*' OR "natural compound*' OR "natural molecule*' $O R$ 'phytochemical*' $O R$ "secondary metabolite*') AND TS = ('diabet' ${ }^{* \prime}$ ) and analysed by a bibliometric software, VOSviewer. The search yielded 3694 publications, which were collectively cited 80,791 times, with an $\mathrm{H}$ index of 117 and 21.9 citations per publication on average. The top-contributing countries were India, the USA, China, South Korea and Brazil. Curcumin, flavanone, resveratrol, carotenoid, polyphenols, flavonol, flavone and berberine were the most frequently cited natural products or compound classes. Our results provide a brief overview of the major directions of natural product research in diabetes up to now and hint on promising avenues for future research.

\section{ARTICLE HISTORY}

Received 3 June 2020

Accepted 28 August 2020

\section{KEYWORDS}

Natural product; phytochemical; diabetes; bibliometric; citation analysis; curcumin; resveratrol 


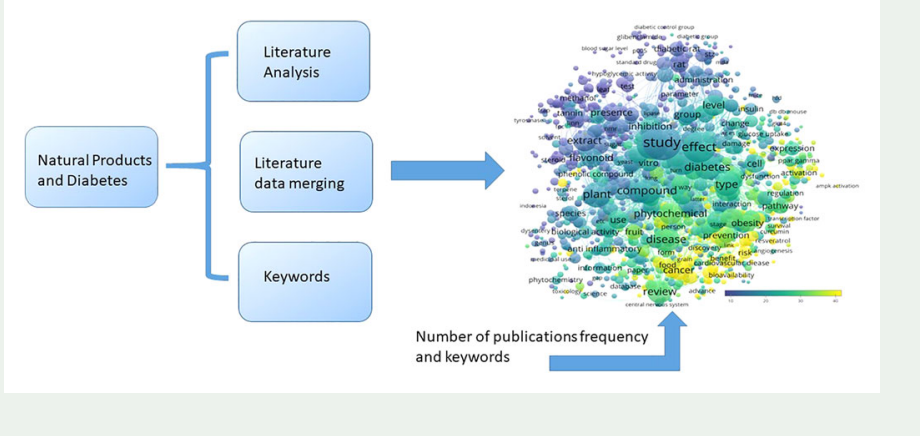

\section{Introduction}

Diabetes is a metabolic chronic disease characterised by elevated blood levels of glucose/sugar because the body cannot produce enough insulin or effectively use the insulin, leading to serious damage to the heart, blood vessels, nerves, eyes and kidneys (https://www.who.int/health-topics/diabetes). There are two types of diabetes: type 1 diabetes (T1DM) and type 2 diabetes (T2DM) (Alberti and Zimmet 1998). T1DM is characterised by deficient insulin production in the body. The most common is T2DM (previously known as adult-onset or non-insulin-dependent diabetes), resulting from the body's ineffective use (peripheral tissue resistance) of insulin (World Health Organization 2016). Diabetes is a major public health concern (Zimmet et al. 2016). According to the Global Report on Diabetes 2016 from WHO, the number of cases as well as the prevalence of diabetes have been steadily growing over the past several decades. In total, around 422 million adults were living with diabetes in 2014, in comparison to 108 million in 1980 globally. Moreover, 1.5 million deaths were due to diabetes in 2012, with an additional 2.2 million deaths because of increasing the risks for cardiovascular and other diabetes-associated diseases (World Health Organization 2016). T1DM cannot be prevented at present. Although T2DM can be reduced by a healthy lifestyle, including a healthy diet, exercise and increased physical activity, avoiding smoking and maintaining a body weight in a healthy range (Lv et al. 2017). There is a lack of optimally acting drugs with lower side effects to treat it (Souto et al. 2011). Therefore, there is intensive research interest in better understanding diabetes and finding better treatment options, including the identification of natural products with anti-diabetic effects (Wang et al. 2014; Ríos et al. 2015; Souto et al. 2019; Vieira, Souto, Sánchez-López, López Machado, Severino, Jose, Santini, Fortuna, et al. 2019; Vieira, Souto, Sánchez-López, López Machado, Severino, Jose, Santini, Silva, et al. 2019).

Many natural products have been used worldwide for controlling blood glucose levels in patients with diabetes. There are several reviews summarising the common natural products used for managing diabetes (Shapiro and Gong 2002; Tiwari and Rao 2002; Ríos et al. 2015; Alam et al. 2018; Choudhury et al. 2018; Salehi et al. 2019). For instance, in Mexico, herbal extracts from Cecropia obtusifolia Bertol. (Cecropiaceae), 
Equisetum myriochaetum Schlecht \& Cham (Equisetaceae), Leptolobium panamense (Benth.) Sch.Rodr. \& A.M.G.Azevedo (syn. Acosmium panamense (Benth.) Yacolev) (Fabaceae), Agarista mexicana (Hemsl.) Judd. (Ericaceae), Cucurbita ficifolia Bouché (Cucurbitaceae), Brickellia veronicaefolia (Kunth) A. Gray (Asteraceae) and Parmentiera aculeata (Kunth) Seem. (Bignoniaceae) are commonly used to lower the blood glucose level for treating diabetes (Andrade-Cetto and Heinrich 2005). In Sri Lanka, one of the most frequently used medicinal plants was reported to be Senna auriculata (L.) Roxb. (Fabaceae) (Sathasivampillai et al. 2017). In South America, Bauhinia forficata Link (Fabaceae), commonly known as 'paw-of-cow', is widely used in ethnomedicine for therapy of diabetes (Pepato et al. 2002). There also are multiple studies well documenting the role in the treatment of diabetes of Abelmoschus esculentus L. (Moench), native of Africa, and grown different countries from Africa to Asia, Southern Europe and America (Dubey and Mishra 2017; Durazzo et al. 2019; Daliu et al. 2020).

The mechanisms of anti-diabetic action include inhibition of $\alpha$-glucosidase and $\alpha$-amylase in the digestive tract, modulation of glucose uptake and the expression of glucose transporters, stimulation of insulin secretion and pancreatic $\beta$-cell proliferation, control of insulin resistance and regulation of oxidative stress (Ríos et al. 2015; Choudhury et al. 2018; Gong et al. 2019). Several anti-diabetic natural product-based drugs are now available in the market, such as Diabecon ${ }^{\circledR}$, Glyoherb $^{\circledR}$ and Diabeta Plus $^{\circledR}$, with each of them comprised of multiple active ingredients (Choudhury et al. 2018). It should be noted that many pieces of evidence for anti-diabetic action of natural products came from in vitro and in vivo preclinical studies, as Alam et al. (2018) reported that between 2005 and 2016, there were 63 such studies and only 16 clinical studies.

With the growing number of publications as well as natural products reported to be useful for treating diabetes, there exists an interest to evaluate the literature in a quantitative way, so that the most productive contributors, common topics and frequent keywords can be identified. For instance, China and India have a long history of practicing traditional Chinese medicine and Ayurveda, respectively. According to 2016 data from World Health Organization, they have 1.3 billion population each, with diabetes prevalence of $9.4 \%$ and $7.8 \%$, respectively (https://www.who.int/diabetes/country-profiles/en/). As a consequence, are these countries more productive in terms of publishing papers on natural products in diabetes research? The current study is aimed to provide an answer to this and other questions along this line. By providing a quantitative overview of the research literature, researchers may have a better understanding of the global research activities in this field, frequently investigated natural products and leading collaborators.

\section{Materials and methods}

\subsection{Data source}

The Web of Science (WoS) online database was queried with the following search string: TS $=$ ('natural product*' OR 'natural compound*' OR 'natural molecule*' OR 'phytochemical*' OR 'secondary metabolite*') AND TS = ('diabet*'). The search identified publications with a combination of these words or their derivatives in their titles, 


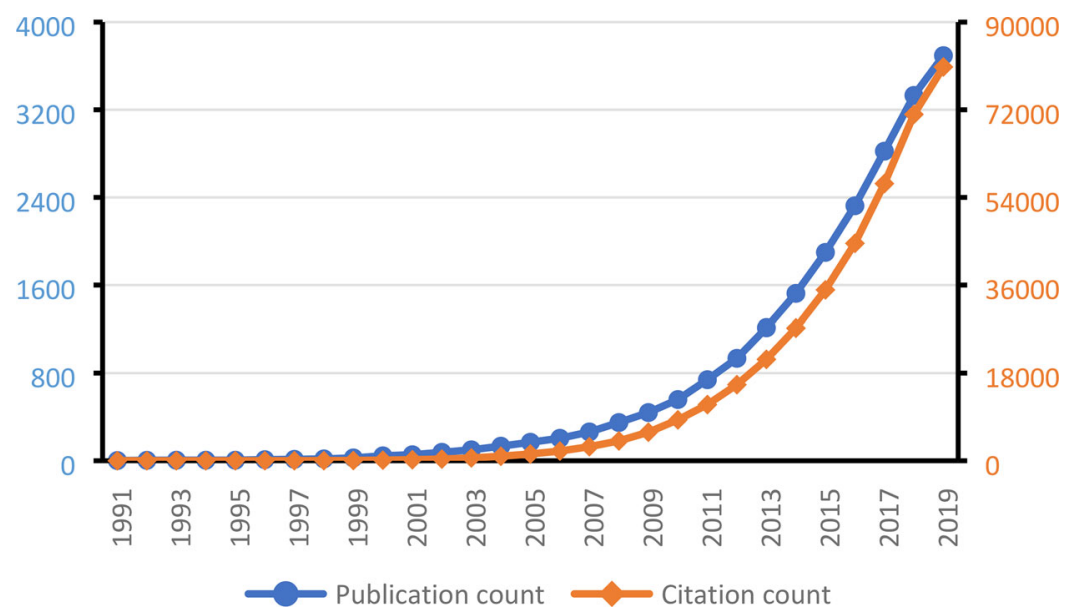

Figure 1. Publication and citation trends of natural products in diabetes research.

abstracts or keywords. The authors' subscription to the database allows the retrieval of documents published as early as in 1956. No additional filters were placed on the search, e.g. publication language, publication type, etc. The identified publications were initially evaluated with the 'Analyse Results' and 'Create Citation Report' functions of the WoS platform, and subsequently exported as 'Full Record and Cited References' to VOSviewer (version 1.6.15), a bibliometric software, for further analysis. As a result, the following parameters were assessed: publication year, publication count, citation count, authorship, institution, country/region, journal, WoS category, document type, language.

\subsection{Term map}

Words from the titles and abstracts were visualised as a term map by VOSviewer with default settings (Van Eck and Waltman 2010, 2011; Waltman et al. 2010). Terms that appeared in at least $0.5 \%(n=19)$ of the analysed publications were visualised. Bubble size represents the number of publications. Bubble colour represents the citations per publication (CPP). Two bubbles are spatially closer if respective terms co-appeared more frequently.

\section{Results and discussion}

The search returned with 3694 publications that were collectively cited 80,791 times, with an $\mathrm{H}$-index of 117 and 21.9 CPP in general. The earliest indexed document was published in 1991 in the Journal of Ethnopharmacology and reported the hypoglycaemic activity of bassic acid, isolated from the rootbark of Sideroxylon obtusifolium subsp. obtusifolium (Roem. \& Schult.) T.D.Penn. (syn. Bumelia sartorum), in diabetic rats through enhanced secretion of insulin (Naik et al. 1991). The cumulative publication and citation counts grew steadily in the 2000s and had a much sharper increase in the 2010s (Figure 1). The growth of citation count was larger than that of publication count. Meanwhile, $67.7 \%$ of the publications were original articles (CPP $=15.3$ ), and 
Table 1. Top 5 most productive authors.

\begin{tabular}{lcc}
\hline Author & Publication count (\% of total) & Citations per publication (CPP) \\
\hline Gokhan Zengin & $36(0.98)$ & 10.6 \\
Kalidas Shetty & $22(0.60)$ & 79.6 \\
Mohamad F. Mahomoodally & $20(0.54)$ & 7.1 \\
Abdurrahman Aktumsek & $15(0.41)$ & 15.8 \\
Seyed Mohammad Nabavi & $15(0.41)$ & 17.6 \\
\hline
\end{tabular}

29.8\% were reviews (CPP $=37.1)$. Most indexed publications were published in English $(n=3656 ; 99.0 \%)$, followed by Spanish $(n=15)$ and Portuguese $(n=8)$.

\subsection{Productive authors}

Table 1 shows the top 5 most productive authors. The most productive author was Gokhan Zengin from Selcuk University, Turkey $(n=36$, CPP $=10.6)$. His most highly cited paper in the current dataset was a paper that reported the total phenolic contents of extracts of Haplophyllum myrtifolium Boiss. (Zengin et al. 2014). On the other hand, the author with highest CPP among the top 5 was Kalidas Shetty, with his most highly cited paper evaluating clonal herbs of Lamiaceae species for inhibiting diabetes and hypertension-related enzymes (Kwon et al. 2006). It should be noted that 'Li J' $(n=28)$ was originally ranked second by WoS 'Analyse Results' function. Upon closer examination, the record should be a combination of $\mathrm{Li}$ Jia who had 13 publications, $\mathrm{Li}$ Jian with 2, Li Jin with 4, Li Jing with 3, Li Jingya with 3 and Li Jun with 3. Similarly, 'Chen J', 'Li Y' and 'Kumar A' ranked 5th to 7th, respectively, by WoS, and were representing multiple authors, each of whom wrote a few papers only. Therefore, they are not listed in Table 1.

\subsection{Productive institutions}

The most productive institution was Chinese Academy of Sciences ( $n=84$; CPP $=$ 21.2). Its most highly cited paper was a review on the resources and biological activities of natural polyphenols ( $\mathrm{Li}$ et al. 2014). Besides the top 5 most productive institutions listed in Table 2, there were 7 more institutions with at least 20 publications, namely National Autonomous University of Mexico (Mexico), Mashhad University of Medical Sciences (Iran), Tehran University of Medical Sciences (Iran), King Saud University (Saudi Arabia), King Abdulaziz University (Saudi Arabia), National Taiwan University (Taiwan, China) and Universiti Putra Malaysia (Malaysia).

\subsection{Productive countries/regions}

Regarding countries/regions, the most productive was India ( $n=717$; CPP $=15.3$ ) (Table 3). The most highly cited paper was a review on the potential health benefits of plant polyphenols as dietary antioxidants against various diseases including diabetes (Pandey and Rizvi 2009). In terms of original research, the most highly cited one was a report that demonstrated the effect of curcumin on enhancing wound healing in rats and mice with diabetes induced by streptozotocin and genetic modification, respectively (Sidhu et al. 1999). Meanwhile, the USA had the highest CPP among the 
Table 2. Top 5 most productive institutions.

\begin{tabular}{lcc}
\hline Institution & Publication count (\% of total) & Citations per publication (CPP) \\
\hline Chinese Academy of Sciences & $84(2.3)$ & 21.2 \\
Council of Scientific and Industrial Research (India) & $61(1.7)$ & 25.4 \\
Selcuk University (Turkey) & $38(1.0)$ & 10.2 \\
Shanghai Institute of Materia Medica & $38(1.0)$ & 24.5 \\
Uniersiti Sains Malaysia & $38(1.0)$ & 13.2 \\
\hline
\end{tabular}

Table 3. Top 5 most productive countries/regions.

\begin{tabular}{lcc}
\hline Country/region & Publication count (\% of total) & Citations per publication (CPP) \\
\hline India & $717(19.4)$ & 15.3 \\
USA & $529(14.3)$ & 47.4 \\
China & $475(12.9)$ & 17.7 \\
South Korea & $228(6.2)$ & 22.1 \\
Brazil & $164(4.4)$ & 16.5
\end{tabular}

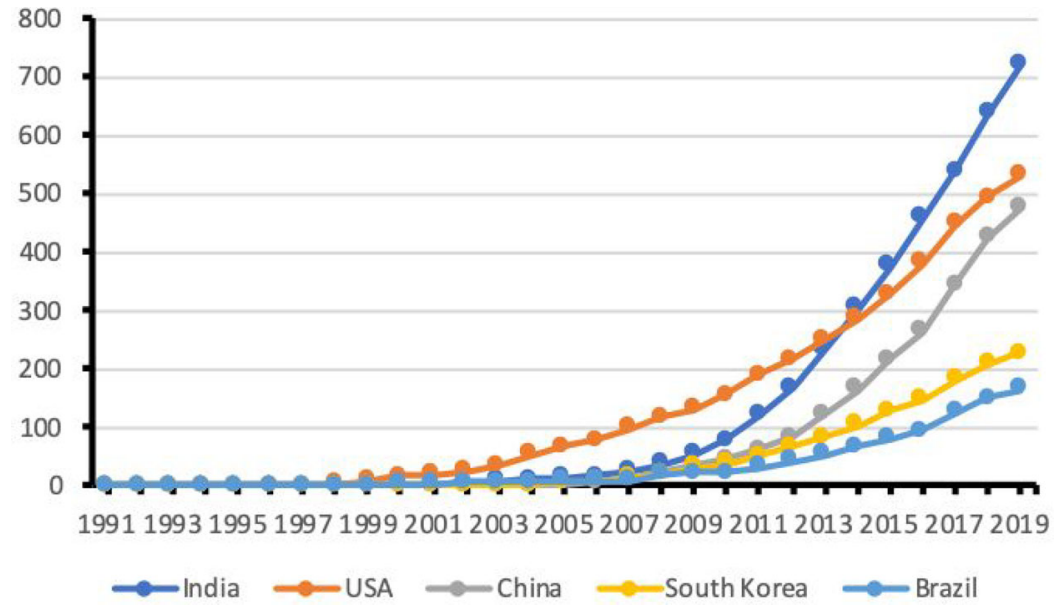

Figure 2. Publication trend of the top 5 most productive countries/regions.

Table 4. Top 5 most productive journals.

\begin{tabular}{lcc}
\hline Journal (impact factor) & Publication count (\% of total) & Citations per publication (CPP) \\
\hline $\begin{array}{l}\text { Journal of } \\
\text { Ethnopharmacology (3.414) }\end{array}$ & $135(3.7)$ & 11.1 \\
$\begin{array}{l}\text { International Journal of } \\
\quad \text { Pharmaceutical Sciences and }\end{array}$ & $98(2.7)$ & 1.6 \\
$\quad$ Research (NA*) & & 17.2 \\
Molecules (3.060) & $82(2.2)$ & 11.4 \\
BMC Complementary and Alternative & $62(1.7)$ & 11.2 \\
$\quad$ Medicine (2.479) & $61(1.7)$ & \\
Evidence-based Complementary and & & \\
$\quad$ Alternative Medicine (1.984) &
\end{tabular}

*Not available

top 5 countries. The most highly cited original research was the evaluation study of Lamiaceae species with Shetty being the corresponding author (Kwon et al. 2006). Figure 2 shows that the lead by the USA was taken by India since 2014, whereas the productivity of China has been growing fast and may take the second place in a few years' time. The growth rate of South Korea and Brazil seem to be similar. 
Table 5. Top 5 most productive WoS categories.

\begin{tabular}{lcc}
\hline WoS category & Publication count (\% of total) & Citations per publication (CPP) \\
\hline Pharmacology and pharmacy & $1135(30.7)$ & 21.3 \\
Chemistry medicinal & $711(19.2)$ & 22.6 \\
Biochemistry and molecular biology & $516(14.0)$ & 31.6 \\
Food science technology & $455(12.3)$ & 23.3 \\
Integrative and complementary medicine & $386(10.4)$ & 17.9 \\
\hline
\end{tabular}

\subsection{Productive journals}

The most productive journal was Journal of Ethnopharmacology $(n=135$; CPP $=11.1)$, which started to publish 40 years ago (Table 4). Its most cited paper was a review of the traditional uses of Psidium guajava, including applications for the treatment of diabetes (Gutiérrez et al. 2008). It should be noted that International Journal of Pharmaceutical Sciences and Research, the only journal among the top 5 without an impact factor, had a much lower CPP than the other 4.

\subsection{Productive WoS categories}

As expected, the largest WoS category for the analysed publications was pharmacology and pharmacy $(n=1135 ;$ CPP $=21.3$ ) (Table 5$)$. The relatively similar publication shares of the top 5 categories not only suggested the diverse research directions in the analysed diabetes literature, but also related to the versatility of the journals, e.g. Journal of Ethnopharmacology is counted by WoS by 4 categories: pharmacology and pharmacy, chemistry medicinal, integrative and complementary medicine and plant sciences. Papers related to biochemistry and molecular biology seemed to have a higher CPP, consistent to the higher CPP received by Molecules, a major journal in this category.

\subsection{Term map}

A total of 1148 terms appeared in at least $0.5 \%(n=19)$ of the 3694 publications and they are visualised as a term map (Figure 3). It should be noticed that animal studies (mainly rats and mice, upper part of Figure 3) and content determination studies of plants (left part) were relatively less cited than the studies involving higher clinical relevance, particularly those also dealing with co-morbidities other than diabetes, such as cardiovascular disease and cancer (lower right part). Some highly cited (CPP > 30) natural products or compound classes included curcumin $(n=100$; CPP $=69.1)$, flavanone $(n=23 ; \mathrm{CPP}=49.1)$, resveratrol $(n=87$; CPP $=47.7)$, carotenoid $(n=72 ; \mathrm{CPP}=$ $44.8)$, polyphenols $(n=28 ; \mathrm{CPP}=42.8)$, flavonol $(n=47 ; \mathrm{CPP}=39.9)$, flavone $(n=33$; $\mathrm{CPP}=38.5)$ and berberine $(n=42 ; \mathrm{CPP}=30.4)$. Their structures are illustrated in Figure 4.

\subsection{Keyword usage}

Over 950 author keywords appeared in at least 3 of the 3694 publications. They covered a variety of topics, some of which were surrounding diabetes as the popular 


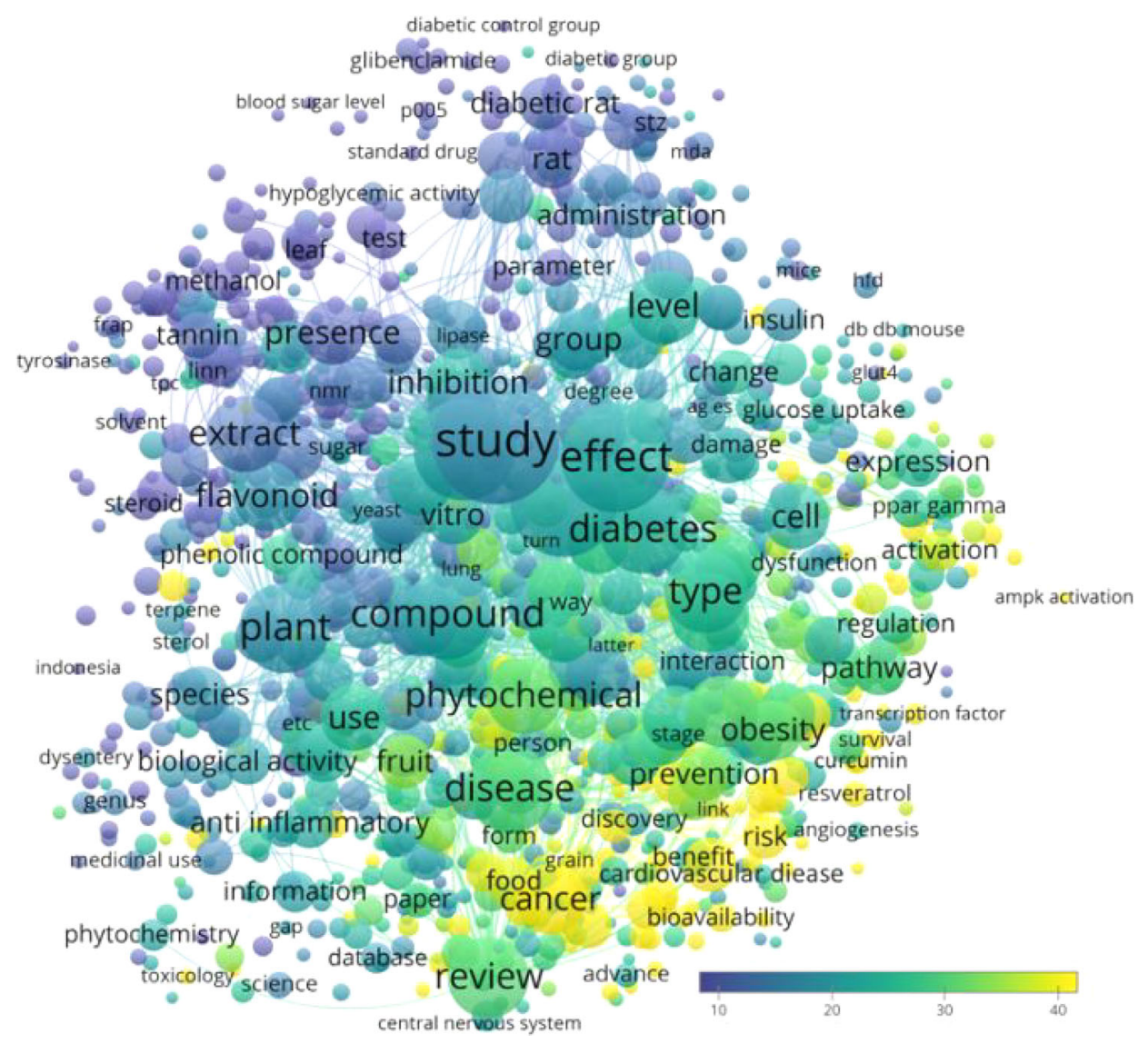

Figure 3. Term map for natural products in diabetes research. Over 1000 terms appeared in at least $0.5 \%(n=19)$ of the analysed publications. Bubble size represents the number of publications. Bubble colour represents the citations per publication (CPP). Two bubbles are closer to each other if the terms co-appeared more frequently.

topics, such as antioxidants, oxidative stress, inflammation and obesity. The top 20 keywords are listed in Table 6. The words 'flavonoids' and 'polyphenols' were natural products that were frequently listed as keywords. Pathways related to $\alpha$-glucosidase and insulin resistance were frequently investigated.

Some commonly mentioned plant species and family names were Moringa oleifera $(n=12, \mathrm{CPP}=19.1)$, cinnamon $(n=8, \mathrm{CPP}=17.8)$, fenugreek $(n=8, \mathrm{CPP}=12.8)$, Lamiaceae $(n=8, \mathrm{CPP}=44.3)$, Carica papaya $(n=7, \mathrm{CPP}=7.9)$, Cucurbitaceae $(n=7$, $\mathrm{CPP}=31.9)$, garlic $(n=7, \mathrm{CPP}=18.3)$, legumes $(n=7, \mathrm{CPP}=61.1)$, pomegranate $(n=7, \mathrm{CPP}=35.4)$, saffron $(n=7, \mathrm{CPP}=15.9)$ and Stevia rebaudiana $(n=7$, CPP $=19.0$ ).

\subsection{Comparison with other studies in the literature}

The current study evaluated the literature of natural products in diabetes research. We found that more than 3600 publications investigated on this topic, with the original article-to-review ratio being 2.3:1. This ratio is larger than that for dietary natural 
<smiles>COc1cc(/C=C/C(=O)CC(=O)/C=C/c2ccc(O)c(OC)c2)ccc1O</smiles>

Curcumin $(n=100, \mathrm{CPP}=68.1)$<smiles>O=C1C[C@H](c2ccccc2)Oc2ccccc21</smiles>

Flavanone $(n=23, \mathrm{CPP}=49.1)$ or

Flavone $(n=33, \mathrm{CPP}=38.5)$<smiles>Oc1ccc(/C=C/c2cc(O)cc(O)c2)cc1</smiles>

$$
\begin{gathered}
\text { Resveratrol } \\
(n=87, \mathrm{CPP}=47.7)
\end{gathered}
$$<smiles>CC1=C(/C=C/C(C)=C/C=C/C(C)=C/C=C/C=C(C)/C=C/C=C(C)/C=C/C2=C(C)CCCC2(C)C)C(C)(C)CCC1</smiles><smiles>O=c1c(O)c(-c2ccc(O)c(O)c2)oc2cc(O)cc(O)c12</smiles>

Quercetin (Polyphenols) ( $n=28, \mathrm{CPP}=42.8)$<smiles>O=c1c(O)c(-c2ccccc2)oc2ccccc12</smiles>

Flavonol

$(n=47, \mathrm{CPP}=39.9)$<smiles>COc1ccc2cc3[n+](cc2c1OC)CCc1cc2c(cc1-3)OCO2</smiles>

Berberine $(n=42, \mathrm{CPP}=30.4)$

Figure 4. Chemical structures of selected highly cited natural products.

Table 6. Top 20 most common author keywords.

\begin{tabular}{lcc}
\hline Keyword & Publication count (\% of total) & Citations per publication (CPP) \\
\hline Diabetes & $468(12.7)$ & 21.0 \\
Antioxidant & $235(6.4)$ & 22.2 \\
Phytochemicals & $221(6.0)$ & 22.6 \\
Diabetes mellitus & $203(5.5)$ & 15.2 \\
Natural products & $155(4.2)$ & 29.5 \\
Oxidative stress & $149(4.0)$ & 25.9 \\
Flavonoids & $133(3.6)$ & 21.9 \\
Obesity & $131(3.5)$ & 32.3 \\
Inflammation & $116(3.1)$ & 29.0 \\
Antioxidants & $110(3.0)$ & 48.1 \\
Anti-diabetic & $109(3.0)$ & 12.2 \\
Type 2 diabetes & $99(2.7)$ & 23.9 \\
Cancer & $98(2.7)$ & 40.1 \\
$\alpha$-Glucosidase & $96(2.6)$ & 16.6 \\
Antioxidant activity & $94(2.5)$ & 20.6 \\
Polyphenols & $88(2.4)$ & 39.3 \\
Insulin resistance & $86(2.3)$ & 24.4 \\
Streptozotocin & $85(2.3)$ & 14.4 \\
Medicinal plants & $80(2.2)$ & 16.7 \\
Phytochemical & $76(2.1)$ & 21.0 \\
\hline
\end{tabular}

product research (1.5:1) (Yeung, Aggarwal, et al. 2018), but smaller than natural products in cancer research (4.0:1) (Yeung, El-Demerdash, et al. 2018). Meanwhile, this ratio seems to be smaller than those of research literatures that are not limited to clinical relevance, such as antioxidants (12.5:1) (Yeung, Tzvetkov, et al. 2019), curcumin 
(10.4:1) (Yeung, Horbańczuk, et al. 2019) and resveratrol (9.5:1) (Yeung, Aggarwal, et al. 2019). The increasing productivity of India and China in the second half of the 2010s is similar to the situation in curcumin literature (Yeung, Horbańczuk, et al. 2019).

It is interesting to notice that International Journal of Pharmaceutical Sciences and Research, which has no impact factor, was the second most productive journal with $\mathrm{CPP}=1.6$. The journal is relatively new, with its first volume published in 2010 , and is open access. Readers can access the full text easily. Perhaps its accessibility can promote its visibility in the short future so that the papers will be cited more.

Meanwhile, it is reassuring to notice from the term map that studies with higher clinical relevance tended to be cited more than animal and in vitro studies. This finding seems to be different from a citation analysis on some medical fields, in which basic research tended to be cited more than clinical research (Van Eck et al. 2013). Many of the lab studies of natural product and ethnopharmacological research are antioxidant assays of specimen, such as food and medicinal plants, some of which may have questionable translational value into clinical settings and are thus rejected by some journals nowadays (Yeung, Heinrich, et al. 2018). It is expected that in the future the more clinically relevant studies will continue to get more citations.

Many natural product-derived chemicals are beneficial for managing diabetes, through various means some of which were identified among the common terms and keywords, e.g. oxidative stress, cytokine and inflammation, insulin and $\alpha$-glucosidase (Alam et al. 2018). Of course, there are many ways to modulate the disease process. For instance, (poly)phenolic compounds are reported to regulate carbohydrate metabolism, improve glucose uptake, protect pancreatic beta cells, enhance insulin action and regulate signalling pathways to cell homeostasis (Dias et al. 2017).

One of the highly cited natural products was curcumin. In diabetic rats and mice, curcumin was found to promote wound healing, improve glycemic control and reverse inflammatory and metabolic derangements (Sidhu et al. 1999; Kowluru and Kanwar 2007; Weisberg et al. 2008). In human randomised controlled trials, consumption of curcumin was reported to reduce the risk of prediabetic individuals of becoming diabetic (Chuengsamarn et al. 2012), lower the atherosclerotic risks in patients with T2DM (Chuengsamarn et al. 2014) and reduce their inflammatory cytokines and markers of oxidative stress (Usharani et al. 2008; Panahi et al. 2017). Another highly cited natural product was resveratrol. It was found to be therapeutic for treating T2DM by being a SIRT1 and Akt activator that improves glucose homeostasis and insulin sensitivity (Milne et al. 2007; Brasnyó et al. 2011; Bhatt et al. 2012). Also, berberine has shown considerable effectiveness in the management of diabetes and other metabolic diseases in vitro, in preclinical in vivo models and in clinical studies (Neag et al. 2018; Belwal et al. 2020; Yeung et al. 2020).

\subsection{Limitations}

One major limitation of the current study is that we only used data from a single database, WoS. Some relevant publications may be indexed by other databases but not in WoS. However, since each database indexes publications and count citations differently, it is not possible for us to merge the presented data, especially the citation 
data, across multiple databases. Future follow-up studies may consider using data generated from different databases to compare with the results reported in this study.

\section{Concluding remarks}

A bibliometric analysis was performed for natural products in diabetes research. Results showed that the literature grew steadily in terms of publication and citation counts in the 2000s and has been growing more quickly in the 2010s. The literature has so far accumulated around 3700 publications. The most productive countries come from Asia, North and South America. China and India have become more productive since the 2010s. The publications were mostly dealing with pharmacology and pharmacy, medicinal chemistry and biochemistry and molecular biology. Animal studies and content determination studies of plants were relatively less cited than studies with direct clinical relevance. $\alpha$-Glucosidase and insulin resistance were among those frequently mentioned keywords. Some highly cited natural products or compound classes included curcumin, flavanone, resveratrol, carotenoid, polyphenols, flavonol, flavone and berberine. Among these, curcumin, resveratrol and carotenoid were more frequently investigated. However, they have not yet been developed into drugs, with potential hindrances from low bioavailability (Dei Cas and Ghidoni 2019) reservation from physicians (Wahner-Roedler et al. 2006) and patenting limitations (Wong and Chan 2014). We anticipate that future research should further validate the efficacy of these natural products on managing diabetes through human studies, and to set the optimal route of administration and dosage, so that the initial promising results can be readily translated into clinical practice. Along this line, we hope that more future studies will thus be published in medical journals reporting their potential benefits in clinical trials.

\section{Author contributions}

Conceptualisation, A.W.K.Y. and A.G.A.; methodology, A.W.K.Y. and A.G.A.; data curation, A.W.K.Y. and A.G.A.; writing-original draft preparation, A.W.K.Y., N.T.T., A.D., A.S. and A.G.A.; visualisation and validation, all authors; writing review and editing, all authors. All authors have read and agreed to the published version of the manuscript.

\section{Ethical approval}

Not applicable.

\section{Consent to participate}

Not applicable.

\section{Disclosure statement}

No potential conflict of interes must be reported by the authors. 


\section{Funding}

Atanas G. Atanasov acknowledges the support of the Polish KNOW (Leading National Research Centre) Scientific Consortium 'Healthy Animal - Safe Food', decision of the Ministry of Science and Higher Education No. 05-1/KNOW2/2015. Dongdong Wang acknowledges the Cultivation project for clinical medicine of the integrated traditional Chinese and western medicine and Cultivation project for education team of internal medicine of the integrated traditional Chinese and western medicine in the first-term subjects with special support in the first-class universities in Guizhou province (Qin Jiao Gao Fa No. 2017-158). Javier Echeverría gratefully acknowledges funding from CONICYT (PAI/ACADEMIA No. 79160109).

\section{ORCID}

Nikolay T. Tzvetkov (D) http://orcid.org/0000-0002-8482-0481

Alessandra Durazzo (D) http://orcid.org/0000-0002-7747-9107

Massimo Lucarini (iD http://orcid.org/0000-0001-6178-9779

Eliana B. Souto (D) http://orcid.org/0000-0002-9737-6017

Antonello Santini (D) http://orcid.org/0000-0001-5505-3327

Dongdong Wang (D) http://orcid.org/0000-0002-6195-4428

Atanas G. Atanasov (D) http://orcid.org/0000-0003-2545-0967

\section{References}

Alam F, Islam MA, Kamal MA, Gan SH. 2018. Updates on managing type 2 diabetes mellitus with natural products: towards antidiabetic drug development. Curr Med Chem. 25(39):5395-5431.

Alberti KGMM, Zimmet PZ. 1998. Definition, diagnosis and classification of diabetes mellitus and its complications. Part 1: diagnosis and classification of diabetes mellitus. Provisional report of a WHO consultation. Diabet Med. 15(7):539-553.

Andrade-Cetto A, Heinrich M. 2005. Mexican plants with hypoglycaemic effect used in the treatment of diabetes. J Ethnopharmacol. 99(3):325-348.

Belwal T, Bisht A, Devkota HP, Ullah H, Khan H, Pandey A, Bhatt ID, Echeverría J. 2020. Phytopharmacology and clinical updates of Berberis species against diabetes and other metabolic diseases. Front Pharmacol. 11:41.

Bhatt JK, Thomas S, Nanjan MJ. 2012. Resveratrol supplementation improves glycemic control in type 2 diabetes mellitus. Nutr Res. 32(7):537-541.

Brasnyó $P$, Molnár GA, Mohás M, Markó L, Laczy B, Cseh J, Mikolás E, Szijártó IA, Mérei A, Halmai $R$, et al. 2011. Resveratrol improves insulin sensitivity, reduces oxidative stress and activates the Akt pathway in type 2 diabetic patients. Br J Nutr. 106(3):383-389.

Choudhury H, Pandey M, Hua CK, Mun CS, Jing JK, Kong L, Ern LY, Ashraf NA, Kit SW, Yee TS, et al. 2018. An update on natural compounds in the remedy of diabetes mellitus: a systematic review. J Tradit Complement Med. 8(3):361-376.

Chuengsamarn S, Rattanamongkolgul S, Luechapudiporn R, Phisalaphong C, Jirawatnotai S. 2012. Curcumin extract for prevention of type 2 diabetes. Diabetes Care. 35(11):2121-2127.

Chuengsamarn S, Rattanamongkolgul S, Phonrat B, Tungtrongchitr R, Jirawatnotai S. 2014. Reduction of atherogenic risk in patients with type 2 diabetes by curcuminoid extract: a randomized controlled trial. J Nutr Biochem. 25(2):144-150.

Daliu P, Annunziata G, Tenore GC, Santini A. 2020. Abscisic acid identification in Okra, Abelmoschus esculentus L. (Moench): perspective nutraceutical use for the treatment of diabetes. Nat Prod Res. 34(1):3-9.

Dei Cas M, Ghidoni R. 2019. Dietary curcumin: correlation between bioavailability and health potential. Nutrients. 11(9):2147. 
Dias TR, Alves MG, Casal S, Oliveira PF, Silva BM. 2017. Promising potential of dietary (poly)phenolic compounds in the prevention and treatment of diabetes mellitus. Curr Med Chem. 24(4):334-354.

Dubey P, Mishra S. 2017. A review on: diabetes and okra (Abelmoschus esculentus). J Med Plants Stud. 5(3):23-26.

Durazzo A, Lucarini M, Novellino E, Souto EB, Daliu P, Santini A. 2019. Abelmoschus esculentus (L.): bioactive components' beneficial properties-focused on antidiabetic role-for sustainable health applications. Molecules. 24(1):38.

Gong X, Ji M, Xu J, Zhang C, Li M. 2019. Hypoglycemic effects of bioactive ingredients from medicine food homology and medicinal health food species used in China. Crit Rev Food Sci Nutr. 60(14):2303-2326.

Gutiérrez RMP, Mitchell S, Solis RV. 2008. Psidium guajava: a review of its traditional uses, phytochemistry and pharmacology. J Ethnopharmacol. 117(1):1-27.

Kowluru RA, Kanwar M. 2007. Effects of curcumin on retinal oxidative stress and inflammation in diabetes. Nutr Metab. 4(1):8.

Kwon Y-II, Vattem DA, Shetty K. 2006. Evaluation of clonal herbs of Lamiaceae species for management of diabetes and hypertension. Asia Pac J Clin Nutr. 15(1):107-118.

Li A-N, Li S, Zhang Y-J, Xu X-R, Chen Y-M, Li H-B. 2014. Resources and biological activities of natural polyphenols. Nutrients. 6(12):6020-6047.

Lv J, Yu C, Guo Y, Bian Z, Yang L, Chen Y, Hu X, Hou W, Chen J, Chen Z, et al. 2017. Adherence to a healthy lifestyle and the risk of type 2 diabetes in Chinese adults. Int J Epidemiol. 46(5): 1410-1420.,

Milne JC, Lambert PD, Schenk S, Carney DP, Smith JJ, Gagne DJ, Jin L, Boss O, Perni RB, Vu CB, et al. 2007. Small molecule activators of SIRT1 as therapeutics for the treatment of type 2 diabetes. Nature. 450(7170):712-716.

Naik SR, Barbosa Filho JM, Dhuley JN, Deshmukh V. 1991. Probable mechanism of hypoglycemic activity of bassic acid, a natural product isolated from Bumelia sartorum. J Ethnopharmacol. 33(1-2):37-44.

Neag MA, Mocan A, Echeverría J, Pop RM, Bocsan Cl, Crişan G, Buzoianu AD. 2018. Berberine: botanical occurrence, traditional uses, extraction methods, and relevance in cardiovascular, metabolic, hepatic, and renal disorders. Front Pharmacol. 9:557.

Panahi Y, Khalili N, Sahebi E, Namazi S, Karimian MS, Majeed M, Sahebkar A. 2017. Antioxidant effects of curcuminoids in patients with type 2 diabetes mellitus: a randomized controlled trial. Inflammopharmacology. 25(1):25-31.

Pandey KB, Rizvi SI. 2009. Plant polyphenols as dietary antioxidants in human health and disease. Oxid Med Cell Longev. 2(5):270-278.

Pepato MT, Keller E, Baviera AM, Kettelhut IC, Vendramini RC, Brunetti IL. 2002. Anti-diabetic activity of Bauhinia forficata decoction in streptozotocin-diabetic rats. J Ethnopharmacol. 81(2):191-197.

Ríos JL, Francini F, Schinella GR. 2015. Natural products for the treatment of type 2 diabetes mellitus. Planta Med. 81(12-13):975-994.

Salehi B, Ata A, Anil Kumar NV, Sharopov F, Ramírez-Alarcón K, Ruiz-Ortega A, Abdulmajid Ayatollahi S, Valere Tsouh Fokou P, Kobarfard F, Amiruddin Zakaria Z, et al. 2019. Antidiabetic potential of medicinal plants and their active components. Biomolecules. 9(10):551.

Sathasivampillai SV, Rajamanoharan PR, Munday M, Heinrich M. 2017. Plants used to treat diabetes in Sri Lankan Siddha Medicine - an ethnopharmacological review of historical and modern sources. J Ethnopharmacol. 198:531-599.

Shapiro K, Gong WC. 2002. Natural products used for diabetes. J Am Pharm Assoc. 42(2): 217-226.

Sidhu GS, Mani H, Gaddipati JP, Singh AK, Seth P, Banaudha KK, Patnaik GK, Maheshwari RK. 1999. Curcumin enhances wound healing in streptozotocin induced diabetic rats and genetically diabetic mice. Wound Repair Regen. 7(5):362-374. 
Souto EB, Souto SB, Campos JR, Severino P, Pashirova TN, Zakharova LY, Silva AM, Durazzo A, Lucarini $M$, Izzo AA, et al. 2019. Nanoparticle delivery systems in the treatment of diabetes complications. Molecules. 24(23):4209.

Souto SB, Souto EB, Braga DC, Medina JL. 2011. Prevention and current onset delay approaches of type 2 diabetes mellitus (T2DM). Eur J Clin Pharmacol. 67(7):653-661.

Tiwari AK, Rao JM. 2002. Diabetes mellitus and multiple therapeutic approaches of phytochemicals: present status and future prospects. Curr Sci. 83:30-38.

Usharani P, Mateen A, Naidu M, Raju Y, Chandra N. 2008. Effect of NCB-02, atorvastatin and placebo on endothelial function, oxidative stress and inflammatory markers in patients with type 2 diabetes mellitus. Drugs R\&D. 9(4):243-250.

Van Eck NJ, Waltman L. 2010. Software survey: VOSviewer, a computer program for bibliometric mapping. Scientometrics. 84(2):523-538.

Van Eck NJ, Waltman L. 2011. Text mining and visualization using VOSviewer. ISSI Newslett. 7: 50-54.

Van Eck NJ, Waltman L, van Raan AF, Klautz RJ, Peul WC. 2013. Citation analysis may severely underestimate the impact of clinical research as compared to basic research. PLoS One. 8(4): e62395.

Vieira R, Souto SB, Sánchez-López E, López Machado A, Severino P, Jose S, Santini A, Fortuna A, García ML, Silva AM. 2019. Sugar-lowering drugs for type 2 diabetes mellitus and metabolic syndrome-review of classical and new compounds: part-I. Pharmaceuticals. 12(4):152.

Vieira R, Souto SB, Sánchez-López E, López Machado A, Severino P, Jose S, Santini A, Silva AM, Fortuna A, García ML. 2019. Sugar-lowering drugs for type 2 diabetes mellitus and metabolic syndrome-strategies for in vivo administration: part-II. J Clin Med. 8(9):1332.

Wahner-Roedler DL, Vincent A, Elkin PL, Loehrer LL, Cha SS, Bauer BA. 2006. Physicians' attitudes toward complementary and alternative medicine and their knowledge of specific therapies: a survey at an academic medical center. Evid Based Complement Alternat Med. 3(4):495-501.

Waltman L, Van Eck NJ, Noyons EC. 2010. A unified approach to mapping and clustering of bibliometric networks. J Informetrics. 4(4):629-635.

Wang L, Waltenberger B, Pferschy-Wenzig E-M, Blunder M, Liu X, Malainer C, Blazevic T, Schwaiger S, Rollinger JM, Heiss EH, et al. 2014. Natural product agonists of peroxisome proliferator-activated receptor gamma (PPAR $\gamma$ ): a review. Biochem Pharmacol. 92(1):73-89.

Weisberg SP, Leibel R, Tortoriello DV. 2008. Dietary curcumin significantly improves obesity-associated inflammation and diabetes in mouse models of diabesity. Endocrinology. 149(7): 3549-3558.

Wong AY-T, Chan AW-K. 2014. Myriad and its implications for patent protection of isolated natural products in the United States. Chin Med. 9(1):17.

World Health Organization. 2016. Global report on diabetes. Geneva: World Health Organization.

Yeung AWK, Aggarwal BB, Barreca D, Battino M, Belwal T, Horbańczuk OK, Berindan-Neagoe I, Bishayee A, Daglia M, Devkota HP, et al. 2018. Dietary natural products and their potential to influence health and disease including animal model studies. Anim Sci Pap Reps. 36(4): 345-358.

Yeung AWK, Aggarwal BB, Orhan IE, Horbanczuk OK, Barreca D, Battino M, Belwal T, Bishayee A, Daglia M, Devkota HP, et al. 2019. Resveratrol, a popular dietary supplement for human and animal health: quantitative research literature analysis - a review. Anim Sci Pap Rep. 37: 103-118.

Yeung AWK, El-Demerdash A, Berindan-Neagoe I, Atanasov AG, Ho Y-S. 2018. Molecular responses of cancers by natural products: modifications of autophagy revealed by literature analysis. Crit Rev Oncog. 23(5-6):347-370.

Yeung AWK, Heinrich M, Atanasov AG. 2018. Ethnopharmacology - a bibliometric analysis of a field of research meandering between medicine and food science? Front Pharmacol. 9:215.

Yeung AWK, Horbańczuk M, Tzvetkov NT, Mocan A, Carradori S, Maggi F, Marchewka J, Sut S, Dall'Acqua S, Gan R-Y, et al. 2019. Curcumin: total-scale analysis of the scientific literature. Molecules. 24(7):1393. 
Yeung AWK, Orhan IE, Aggarwal BB, Battino M, Belwal T, Bishayee A, Daglia M, Devkota HP, ElDemerdash A, Balacheva AA, et al. 2020. Berberine, a popular dietary supplement for human and animal health: quantitative research literature analysis-a review. Anim Sci Pap Rep. 38(1): 5-19.

Yeung AWK, Tzvetkov NT, El-Tawil OS, Bungău SG, Abdel-Daim MM, Atanasov AG. 2019. Antioxidants: scientific literature landscape analysis. Oxid Med Cell Longev. 2019:8278454.

Zengin G, Sarikurkcu C, Aktumsek A, Ceylan R, Ceylan O. 2014. A comprehensive study on phytochemical characterization of Haplophyllum myrtifolium Boiss. endemic to Turkey and its inhibitory potential against key enzymes involved in Alzheimer, skin diseases and type II diabetes. Ind Crops Prod. 53:244-251.

Zimmet P, Alberti KG, Magliano DJ, Bennett PH. 2016. Diabetes mellitus statistics on prevalence and mortality: facts and fallacies. Nat Rev Endocrinol. 12(10):616-622. 